\title{
Application of Nanomechanical Methods in Investigation of C-S-H Gel/Cement Grain Interface
}

\author{
Jing Xu \\ Key Laboratory of Advanced Civil Engineering Materials, Tongji University, Ministry of Education \\ David J. Corr and Surendra P. Shah \\ Department of Civil and Environmental Engineering, Northwestern University
}

\begin{abstract}
Investigation on the mechanical properties of cement-based materials at micron and submicron scales is important for understanding the overall performance, particularly of high-performance concrete (HPC). Due to low water-tocement ratio of HPC, a large amount of unhydrated cement grains remain in matrix, and a significant impact of the interface between $\mathrm{C}-\mathrm{S}-\mathrm{H}$ gel and cement grains on concrete behavior could be expected. Recent progress in experimental nanomechanics opens new access to nanoengineering of cement-based composites. In this paper, nanoindentation and viscoelastic modulus mapping were used to study the interfacial properties. The interface width measured by modulus mapping was around $200 \mathrm{~nm}$ as compared to a rough estimation of less than $5 \mu \mathrm{m}$ by nanoindentation, due to the fact that two orders of magnitude increase in spatial resolution could be achieved with modulus mapping.
\end{abstract}

Keywords: cement-based materials, nanomechanical properties, interface.

\section{INTRODUCTION}

Over the last 20 years, high-performance concrete (HPC) has been developed and become an important product in industrial and structural application, owing to its outstanding properties, such as high strength, excellent durability, high volume stability, and workability (Shah \& Ahmad, 1994). The superior performance of HPC has been achieved by tailoring its composition and microstructure, which in turn led to numerous comprehensive investigations on concrete properties at micron and sub-micron levels (Reda, Shrive, \& Gilliott, 1999; Richard \& Cheyrezy, 1995).

It is well known that concrete is a multiphase composite material in multiple scale levels. The heterogeneity can be estimated by a three-level model (Constantinides \& Ulm, 2004; Xu \& Yao, 2011). In level I $\left(10^{-2}-10^{0} \mathrm{~m}\right)$, the material can be viewed as a three-phase system: a mortar matrix, coarse aggregate as dispersion strengthened particles, and the aggregate/matrix interfacial transition zone (ITZ). In level II $\left(10^{-4}-10^{-2} \mathrm{~m}\right)$, sand particles contribute to the heterogeneous nature of this scale. This level can be considered as representative of mortar, which is composed of three phases: a cement paste matrix, sand inclusions, and surrounding ITZ. For level III $\left(10^{-6}-10^{-4} \mathrm{~m}\right)$, the $\mathrm{C}-\mathrm{S}-\mathrm{H}$ matrix together with large $\mathrm{Ca}(\mathrm{OH})_{2}$ crystals, unhydrated cement clinker, and micropores in the case of high water-to-cement (w/c) ratios forms the cement paste. At this level, the unhydrated cement clinker can be considered as strengthened hard particles dispersed in the matrix of hydration products, which is mainly composed of $\mathrm{C}-\mathrm{S}-\mathrm{H}$ gel. Therefore, the presence of interface between $\mathrm{C}-\mathrm{S}-\mathrm{H}$ and unhydrated cement grains should also be taken into account.

For levels I and II, the interfacial phases are generally well accepted and understood, due to the relatively large characteristic length scale of constituents that can be directly observed by microscopy imaging techniques. For level III, however, the interface between cement particles and $\mathrm{C}-\mathrm{S}-\mathrm{H}$ gel has not been investigated to the same extent, and studies are mainly restricted to $\mathrm{C}-\mathrm{S}-\mathrm{H}$ phase or cement clinker with plentiful literatures available (Acker, 2001; Constantinides \& Ulm, 2007; Constantinides, Ulm, \& Van Vliet, 2003; Davydov, Jirásek, \& Kopecký, 2011; DeJong \& Ulm, 2007; Jennings, Thomas, Gevrenov, Constantinides, \& Ulm, 2007; Jones, Grasley, \& Ohlhausen, 2012; Mondal, Shah, \& Marks, 2007, 2008; Vandamme, Ulm, \& Fonollosa, 2010; Velez, Maximilien, Damidot, Fantozzi, \& Sorrentino, 2001). On the contrary, the main feature of HPC is its ultra-low w/c ratio that leads to a large amount of unhydrated cement residues. Thus an increase of volume ratio of interfacial phase between $\mathrm{C}-\mathrm{S}-\mathrm{H}$ and unhydrated cement clinker is expected in HPC. This increase of interfacial phase may have a significant impact on concrete properties, particularly the mechanical behavior, and an in-depth investigation is needed. 
With the development of new techniques and instruments, one can explore the mechanical properties of materials at nanoscale and microscale, such as the behavior under loading, the initiation of microcracking and fracture, and even the phase characteristics. Three different techniques have been developed by "Triboindenter," which is commercially available, for these studies (Tribollndenter User Manual, 2006): (1) the depth sensing nanoindentation; (2) nanoscratch involving highly dynamic surface deformation; (3) quantitative modulus mapping in the form of scanning probe microscopy (SPM). The nanoindentation and nanoscratch are "destructive" strategies while the modulus mapping is considered as "nondestructive."

In this study, multiple methods were used to determine the nanomechanical properties of the interface between cement particles and $\mathrm{C}-\mathrm{S}-\mathrm{H}$ gel in cement paste with a low w/c ratio. Besides, the investigation in this paper was mainly focused on cement paste in early age.

\section{SAMPLE PREPARATION}

\subsection{Materials and procedures}

Type I Portland cement was used throughout. Cement paste with a water-to-cement ratio (w/c) of 0.28 was prepared. The samples were cast in prismatic molds of $5 \mathrm{~mm} \times 5 \mathrm{~mm} \times 15 \mathrm{~mm}$. After $24 \mathrm{~h}$ curing in a $100 \%$ humidity room with temperature $20 \pm 2^{\circ} \mathrm{C}$, the samples were demolded and then further cured for 2 days. At the end of curing, the 15-mm-thick samples were then cut into approximately 3-mm-thick slices with a diamond saw. The cut slices were immersed in ethanol for $24 \mathrm{~h}$ to stop further hydration. Then the slices were removed from the ethanol and were subjected to a heat treatment (drying) of $60^{\circ} \mathrm{C}$ for $24 \mathrm{~h}$.

For a reliable measure of the local mechanical properties, the sample must have a flat and smooth surface. All the samples were initially ground on Buehler-Met II paper disks with gradation of 34.2, $22.1,14.5$, and $6.5 \mu \mathrm{m}$, successively. Approximate grinding time on each gradation was $5 \mathrm{~min}$, and water was used as the cooling medium and lubricant. In the following steps, Buehler diamond suspensions in ethanol of gradations $6,3,1$, and $0.3 \mu \mathrm{m}$ were used as polishing liquids on a Buehler Consumables texmat cloth. The polishing time was 30 min for each of the diamond polishing steps. Finally, an ultrasonic bath cleaning in ethanol was performed for $10 \mathrm{~min}$ to remove all dust and diamond particles. Samples were stored in a container after preparation, and the surface quality was confirmed by optical microscopy (Figure 1).

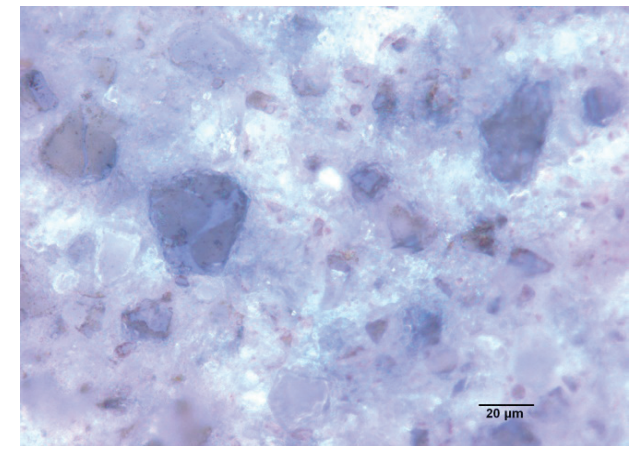

Figure 1. Optical microscopy image of sample surface after polishing.

\subsection{Atomic force microscopy}

The polished samples were further evaluated by AFM (Bruker AXS Dimension ICON) to obtain the surface topographic information. In AFM, a silicon tip was used with a cantilever. All the samples were scanned using the tapping mode to obtain a topographic map, and the scanning was performed with an amplitude set point of $250 \mathrm{mV}$ and a scan rate of $0.75 \mathrm{~Hz}$. Due to the highly variation of the microstructure heterogeneity, the scans were chosen on phases of unhydrated cement grains and hydration products (mainly $\mathrm{C}-\mathrm{S}-\mathrm{H}$ gel), respectively. A total of five scans were conducted for scanning on each phase.

Following the AFM imaging procedure, each image was digitally analyzed to extract a roughness value. Before calculating the roughness, a linear slope correction was performed to account for an alignment difference between the reference plane of AFM imaging and the overall slope of the sample surface. The preferred parameter for roughness was a root mean-squared (RMS) average of the topography of the surface $\left(R_{\mathrm{q}}\right)$. The AFM results of roughness provide a reference for the following nanomechanical tests.

\section{NANOMECHANICAL MEASUREMENTS}

\subsection{Nanoindentation}

Triboindenter (Hysitron, Minneapolis, MN, USA) fitted with a Berkovitch tip (tip radius of $0.6 \mu \mathrm{m}$, angle of $142.3^{\circ}$ ) was used. During this test, the indenter came into contact with the sample surface with a trapezoidal load function, as defined by a loading time of $5 \mathrm{~s}$, a holding time of $2 \mathrm{~s}$ at a maximum load of $1.2 \mathrm{mN}$, and an unloading time of $5 \mathrm{~s}$. Figure 2 presents typical loaddepth curves and the image of an indent mark on $\mathrm{C}-\mathrm{S}-\mathrm{H}$ gel after nanoindentation captured with indenter tip of the Triboindenter. Irregular nanoindentation curves due to the presence of voids and cracking of the sample were discarded. By applying a continuum scale model, the initial unloading stiffness $S$ is given as follows:

$$
S=\frac{\mathrm{d} p}{\mathrm{~d} h}=\frac{2}{\sqrt{\Pi}} E_{\mathrm{r}} \sqrt{A},
$$


where $A$ is the projected contact area at the peak load $P_{\max }$ and can be extrapolated by the Oliver and Pharr method (Oliver \& Pharr, 1992), $E_{r}$ is the reduced elastic modulus, which can be determined by nanoindentation. Then the elastic modulus $E$ of the sample can be calculated by

$$
E=\left(1-v^{2}\right) \times\left[\frac{1}{E_{r}}-\frac{\left(1-v_{\mathrm{i}}^{2}\right)}{E_{\mathrm{i}}}\right]^{-1},
$$

where $E_{\mathrm{i}}$ and $v_{\mathrm{i}}$ are Young's modulus and Poisson's ratio of the indenter, respectively. For the indenter used in the present experiment, the elastic modulus $E_{i}=1140 \mathrm{GPa}$ and the Poisson's ratio $v_{i}=0.07 . v$ is Poisson's ratio of the sample. The suggested value of $v$ is 0.24 , which was used in this study to calculate $E$ (Sorelli, Constantinides, Ulm, \& Toutlemonde, 2008). The hardness $H$ has the definition as follows:

$$
H=\frac{P_{\max }}{A} \text {. }
$$

Statistical grid nanoindentation tests were carried out across the interface between unhydrated cement grain and $\mathrm{C}-\mathrm{S}-\mathrm{H}$ gel. The spacing between the indents was 3 and $5 \mu \mathrm{m}$ in the lateral and vertical directions, respectively. The indent areas had the dimensions of $30 \mu \mathrm{m} \times 10 \mu \mathrm{m}$, as shown in Figure 3 . Therefore, 33 indents were performed at each studied area.

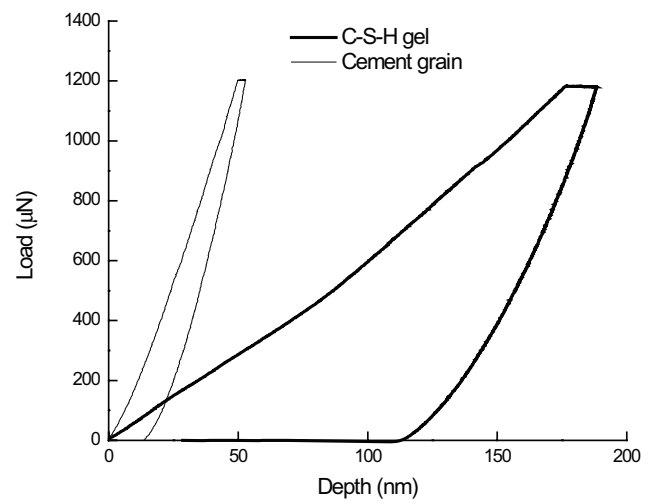

(a)

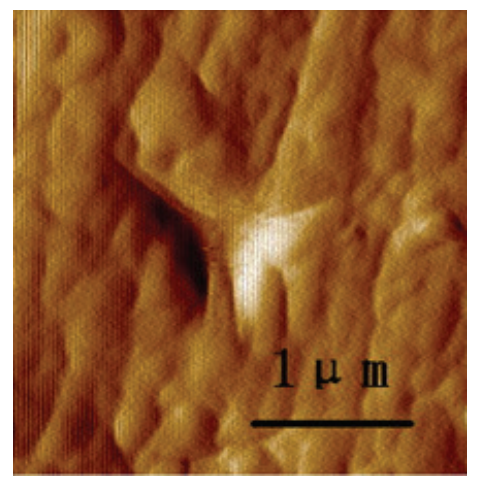

(b)

Figure 2. Typical nanoindentation on cement paste. (a) Load-depth curves of different phases. (b) Indent mark on C-S-H gel.
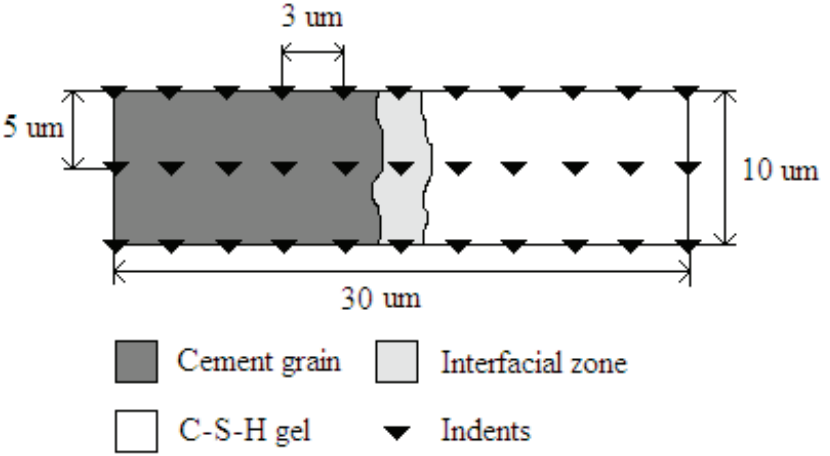

Figure 3. Grid nanoindentation across the interface between $\mathrm{C}-\mathrm{S}-\mathrm{H}$ gel and cement grain.

\subsection{Modulus mapping}

Quantitative modulus mapping in the form of scanning probe microscopy images is acquired using the direct force modulation (nanoDMA ${ }^{R}$ ) operating mode of a TriboScope nanoindenter (Hysitron). The schematic representation of the instrument configuration and dynamical mode is shown in Figure 4. More specifically, a quasi-static force (DC force) acting on the spring-suspended center plate of the forcedisplacement transducer of the nanoindenter was superimposed by a sinusoidal force (AC force) with a frequency of $200 \mathrm{~Hz}$. A Berkovitch tip was attached

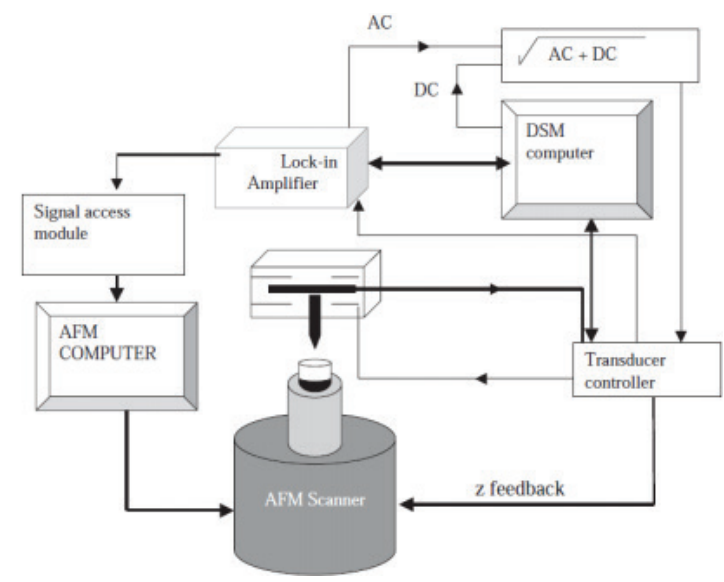

(a)

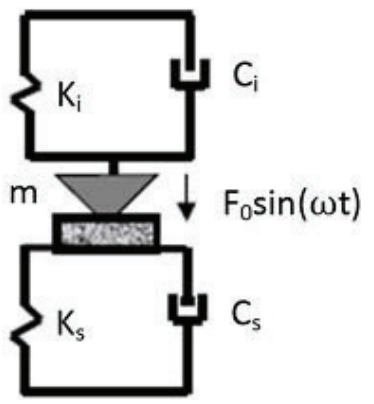

(b)

Figure 4. Schematic of modulus mapping technique. (a) Instrument configuration. (b) Dynamical mode. 
to this transducer. A dual-channel lock-in amplifier was utilized to analyze the sample response, yielding displacement amplitude and the phase shift between the AC force and the displacement. The contact stiffness and material damping were calculated from the amplitude and phase shift using a dynamic model. The modulus mapping technique was calibrated using a standard quartz sample with $69.7 \mathrm{GPa}$ elastic modulus. The tip contact radius is determined by calibration on a quartz standard.

The mode of direct force modulation can be modeled as force applied to a mass that is attached to two fixed Voigt elements (Balooch et al., 2004). One Voigt element represents stiffness and damping of the transducer, and the other represents the same quantities for the contact. The relevant equation of motion is as follows:

$$
F_{\mathrm{e}}(t)=F_{0} \sin (\omega t)=m\left(\frac{\mathrm{d}^{2} z}{\mathrm{~d} t^{2}}\right)+\beta\left(\frac{\mathrm{d} z}{\mathrm{~d} t}\right)+k z,
$$

where $F_{e}$ is the electrostatic force acting on the center plate, $F_{0}{ }^{e}$ is the amplitude of the applied sinusoidal force, $\omega$ is the angular frequency, $m$ is the moving mass of the transducer, $\beta=\beta_{\mathrm{t}}+\beta_{\mathrm{s}}$ is the combined damping coefficient of the indenter and sample, $k=k_{\mathrm{t}}+k_{\mathrm{s}}$ is the combined stiffness of transducer and contact, $z$ is the resulting sinusoidal displacement, and $t$ is time. The solution to this differential equation is

$$
z=z_{0} \sin (\omega t+\varphi),
$$

where the displacement amplitude, $z_{0}$, is given by the dynamical compliance function

$$
z_{0}=\frac{F_{0}}{\left[\left(k-m \omega^{2}\right)^{2}+(\beta \omega)^{2}\right]^{\frac{1}{2}}},
$$

where the phase $\varphi$ of the displacement is dictated by

$$
\tan (\varphi)=-\frac{\beta \omega}{k-m \omega^{2}} .
$$

Determination of $m, \beta_{\mathrm{t}}$, and $k_{\mathrm{t}}$ is accomplished by nonlinear curve fitting of the dynamic compliance vs. frequency trace obtained in air. The nominal contact force is determined solely by the indenter spring deflection and is maintained at contact value $3.5 \mu \mathrm{N}$ by the image feedback controller. The amplitude of the modulated electrostatic force is set to $4.0 \mu \mathrm{N}$, which is large enough to maintain good signal-to-noise ratio for all the material phases of the sample but sufficiently small to prevent intermittent contact. Nominal contact force, displacement amplitude, displacement phase, and topography are signals available for recording at each of the $256 \times 256$ pixels of the imaging process. The storage and loss components of the complex contact stiffness are extracted from the spatially correlated set of amplitude and phase images to generate quantitative stiffness maps

$$
\begin{aligned}
K^{\prime} & =k_{\mathrm{c}}, \\
K^{\prime \prime} & =\beta_{\mathrm{c}} \omega .
\end{aligned}
$$

Converting this data to quantitative modulus maps required knowledge of the contact radius at each pixel. Rearranged of the equations of Hertzian theory yields the following relationship for the contact radius:

$$
a=\sqrt{\frac{3 F R}{2 K^{\prime}}}
$$

where $F$ corresponds to the nominal contact force, and $R$ is the tip radius. The storage modulus can then be formulated as

$$
E^{\prime}=\frac{K^{\prime}}{2 a}
$$

and the loss modulus as

$$
E^{\prime \prime}=\frac{K^{\prime \prime}}{2 a}
$$

Before modulus mapping measurements, in situ scanning probe microscopy (SPM) provided by Triboindenter was used to indentify one specific unhydrated cement grain. Modulus mapping with a scanning size of $15 \mu \mathrm{m} \times 15 \mu \mathrm{m}$ was carried out across the interface between unhydrated cement grain and $\mathrm{C}-\mathrm{S}-\mathrm{H}$ gel.

\section{RESULTS}

\subsection{Nanoindentation}

Previous studies have shown that the indentation depth should be larger than the RMS roughness to ensure the accuracy of nanoindentation results (Miller, Bobko, Vandamme, \& Ulm, 2008; Sakulich \& Li, 2011; Xiao, Li, Sun, Lange, \& Shah, 2013). In this study, the nanoindentation was performed on two distinctive phases: unhydrated cement grain and hydration products (mainly $\mathrm{C}-\mathrm{S}-\mathrm{H}$ gel). According to Miller et al. (2008), the scanning size should be at least 200 times of the average depth of indentation. The average depth of indents on hydration products was $180 \mathrm{~nm}$ as compared to $60 \mathrm{~nm}$ on cement grains. Thus, the scanning sizes on hydration products, and cement grains were selected as 40 and 15 um, respectively. A comparison of the 3D topography images obtained by the AFM at hydration products and cement grains is presented in Figure 5. The average RMS values of five scans at each location of the sample are given in Table 1. The average indentation depth on both of the hydration products and cement grains is three times 
more than surface roughness and should be sufficient to avoid effects of roughness (Xiao et al., 2013).

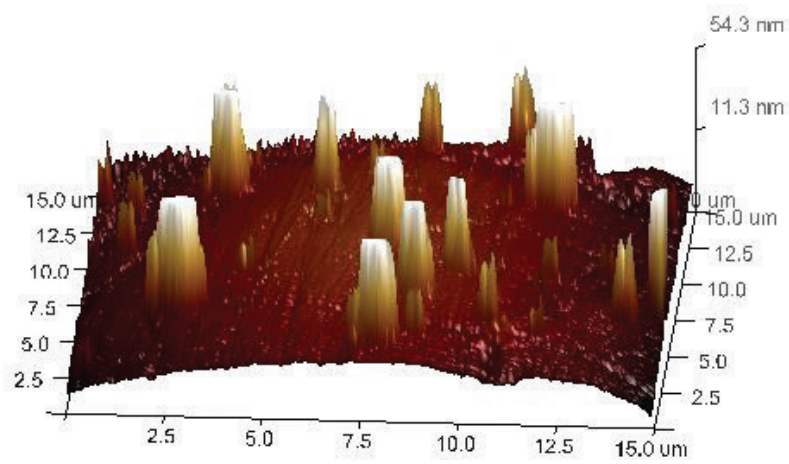

(a)

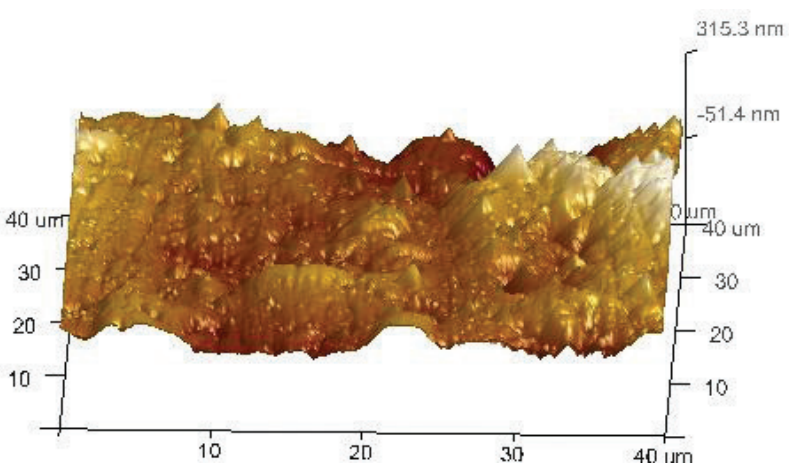

(b)

Figure 5. AFM 3D topography images on cement paste. (a) Cement grain. (b) $\mathrm{C}-\mathrm{S}-\mathrm{H}$ gel.

Table 1. RMS roughness measurement for multiple phases in cement paste.

\begin{tabular}{lccc}
\hline $\begin{array}{l}\text { Scanning } \\
\text { location }\end{array}$ & $\begin{array}{c}\text { Scanning } \\
\text { size } \\
(\boldsymbol{\mu m})\end{array}$ & $\begin{array}{c}\text { Average } \\
\text { indentation } \\
\text { Depth }(\mathbf{n m})\end{array}$ & $\begin{array}{c}\text { Average RMS } \\
\text { roughness } \\
(\mathbf{n m})\end{array}$ \\
\hline $\begin{array}{l}\text { Hydration products } \\
\text { (mainly C-S-H gel) }\end{array}$ & $40 \times 40$ & $180.3 \pm 6.1$ & $59.4 \pm 17.0$ \\
Cement grains & $15 \times 15$ & $57.8 \pm 3.8$ & $12.7 \pm 7.3$ \\
\hline
\end{tabular}

For cement paste at 3 days, the areas on the pastes that contain the interface between cement grains and $\mathrm{C}-\mathrm{S}-\mathrm{H}$ gel were selected for grid indentation (Figure 6a). Figure $6 \mathrm{~b}$ shows the contour maps of indentation modulus of the interfacial regions. It can be observed that the values of interface fall in between the cement grains (red areas) and $\mathrm{C}-\mathrm{S}-\mathrm{H}$ gel (deep blue areas). Figure $6 \mathrm{c}$ shows the indentation modulus distributions with the distances across interfacial region. The modulus of $\mathrm{C}-\mathrm{S}-\mathrm{H}$ gel was around $30 \mathrm{GPa}$, while the modulus variation of cement grain was between 80 and $100 \mathrm{GPa}$. This is in consistent with previous researches (Acker, 2001; Constantinides \& Ulm, 2004; DeJong \& Ulm, 2007; Mondal et al., 2007; Sorelli et al., 2008; Velez et al., 2001). The thickness of the interface was estimated by the sharp variation in indentation modulus with the distance from the cement grain. For both of control and n-Si modified pastes, the interface widths were roughly estimated as less than $5 \mu \mathrm{m}$. The mean value of indentation modulus of the interface was observed as $50 \mathrm{GPa}$.

Figure $7 \mathrm{a}$ shows the contour maps of indentation hardness of the interfacial regions. It was found that the characterization of indentation hardness distribution was close to that of indentation modulus. The widths of interfaces obtained from the hardness distribution (Figure $7 \mathrm{~b}$ ) were also in a good agreement with that from the modulus distribution (Figure 6c). On the contrary, the indentation hardness values obtained from interface was found to be $2 \mathrm{GPa}$.

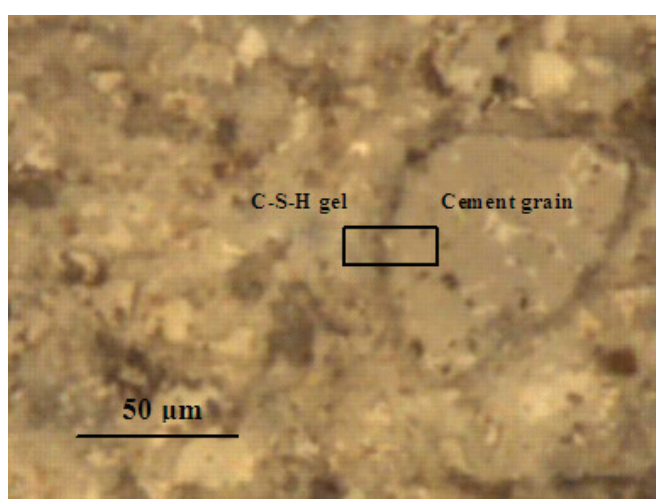

(a)

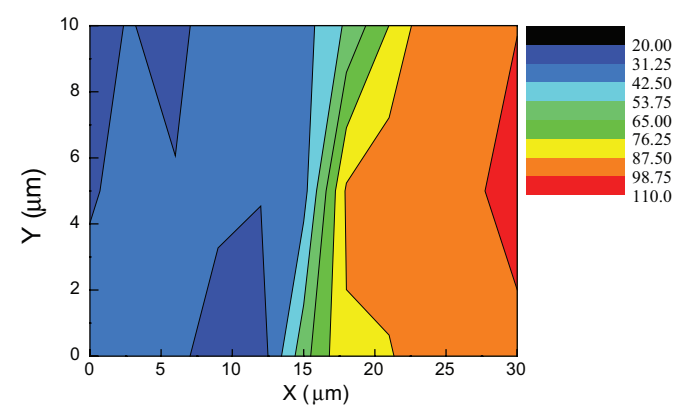

(b)

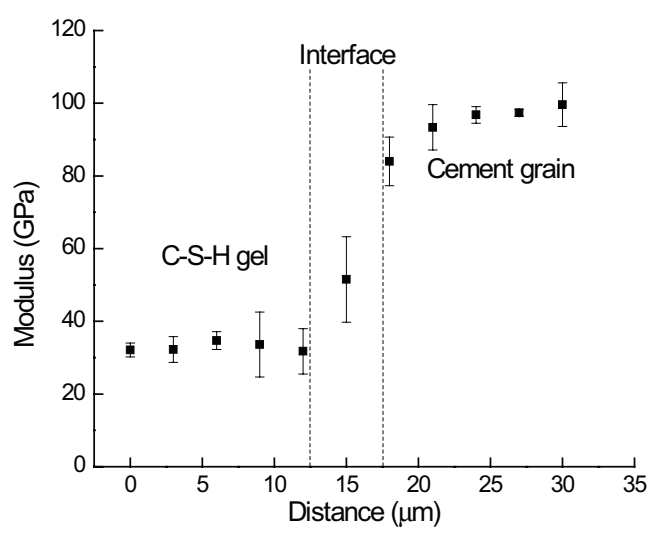

(c)

Figure 6. Grid nanonindentation modulus on interface between C-S-H gel and cement grain. (a) Control paste. (b) Contour map of modulus (control). (c) Modulus distribution (Control). 


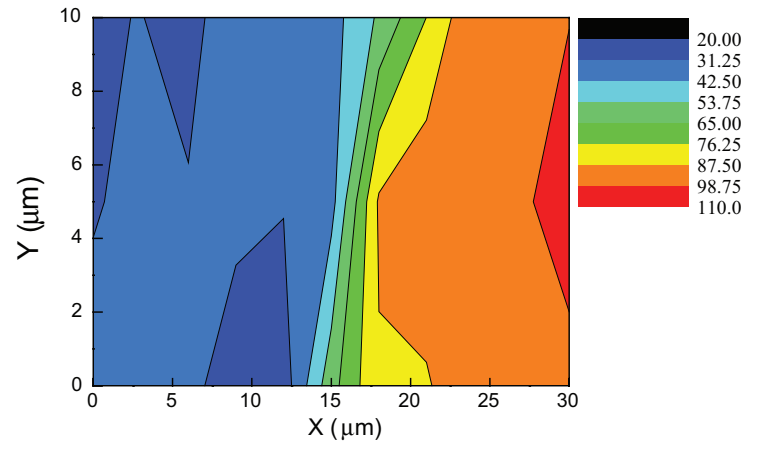

(a)

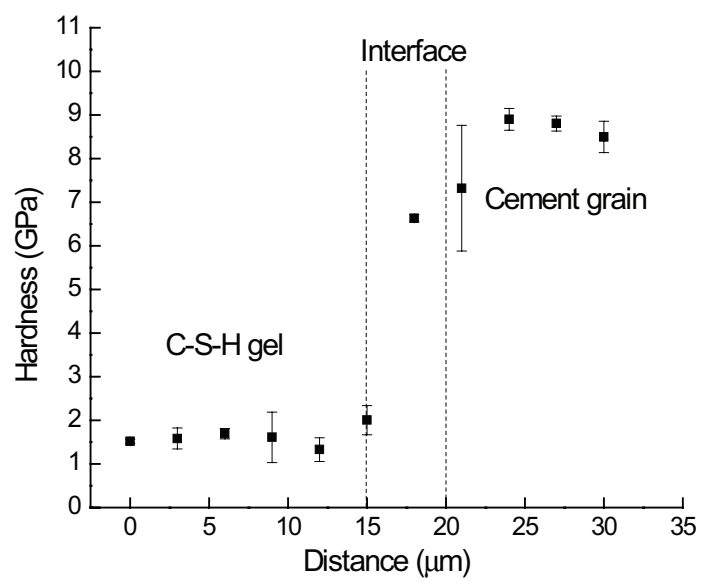

(b)

Figure 7. Grid nanonindentation hardness on interface between $\mathrm{C}-\mathrm{S}-\mathrm{H}$ gel and cement grain. (a) Contour map of hardness (Control). (b) Hardness distribution (Control).

\subsection{Modulus mapping}

The image capability of the Triboindenter can provide an effective method to examine the different phases. Figure 8 shows topographical maps of areas in cement pastes, which contain cement grain, interface, and $\mathrm{C}-\mathrm{S}-\mathrm{H}$ gel, as obtained by SPM. The color scale is proportional to the height variation (z-scale of $1500 \mathrm{~nm}$ ). Close to the interface a step in height resulted from polishing.

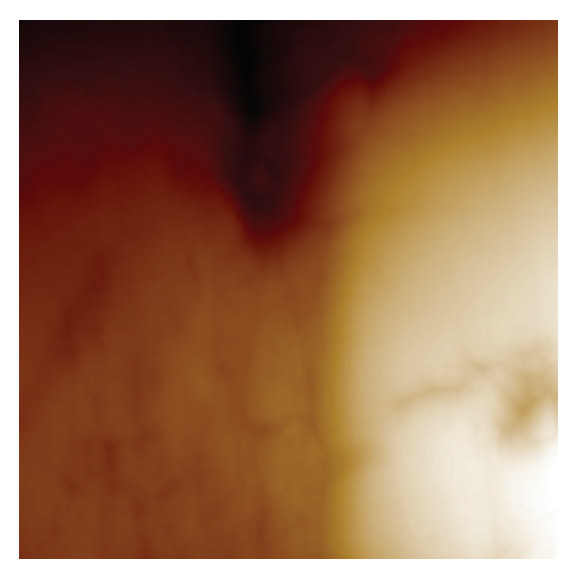

Figure 8. SPM topography images of interface between C-S-H gel and cement grain.
Figure $9 a$ and $b$ is the storage and loss modulus images of the area displayed in Figure 8. For $\mathrm{C}-\mathrm{S}-\mathrm{H}$ gel, the loss component was comparable with storage component; for cement grain, however, the loss component was much lower than storage component. The damping coefficient was larger for $\mathrm{C}-\mathrm{S}-\mathrm{H}$ gel than cement grain, suggesting that gel is more viscoelastic than cement grain. Appreciable local variations in both gel and cement grain were evident from the cross-sections drawn across the interface, as shown in Figure 9c and d. Compared with loss modulus, more significant difference between gel and cement grain could be observed by storage modulus. The $\mathrm{C}-\mathrm{S}-\mathrm{H}$ gel storage modulus variation was between 20 and $50 \mathrm{GPa}$. The range of storage modulus for cement grain was between 70 and $120 \mathrm{GPa}$. On the contrary, the storage modulus curves could also be used to determine the width of interface, as shown in Figure 10. The data were analyzed by sigmoidal curve fitting. A tangent line with the inflexion point of the curve as the tangent point could be drawn, resulting in two intersections with the extension of base lines, and the region between the two intersections was the interface. By measuring the change in properties across 256 cross-sectional lines accessible on a single image, the function is shown in Figure 11. Gaussian distribution function was used to fit the data, and the most probable width of interface was found to be $230 \mathrm{~nm}$. Meanwhile, the average value of the interface at each cross-sectional line was also calculated. The distribution functions for all samples studied are shown in Figure 12. Two peaks were observed for the modulus distribution of interface.
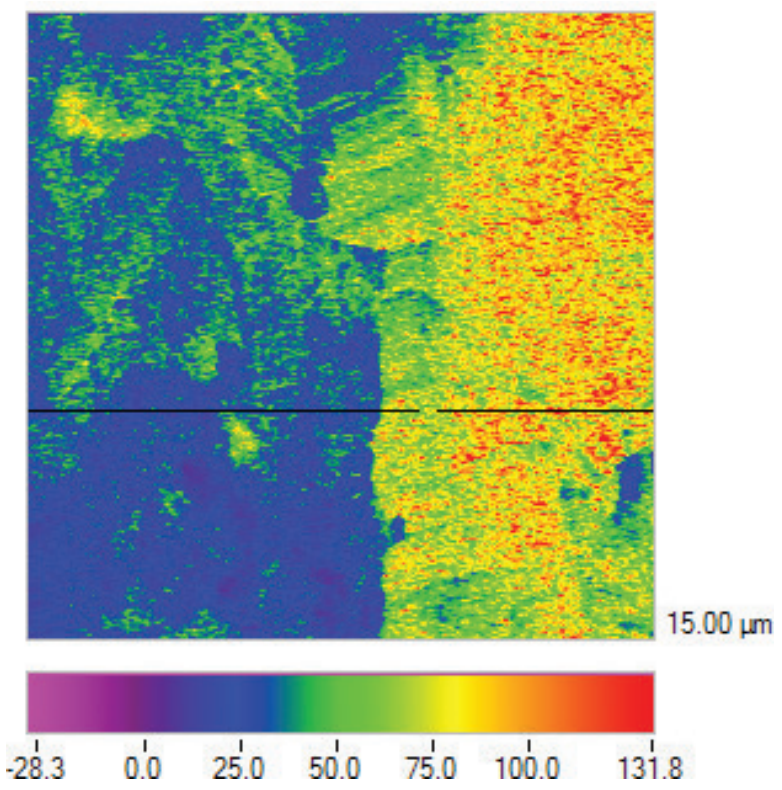

(a) 

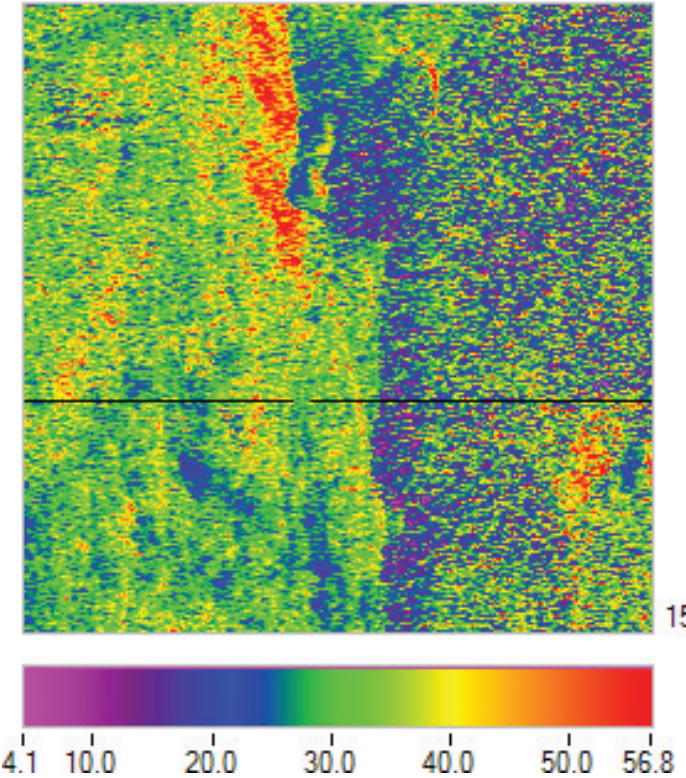

(b)

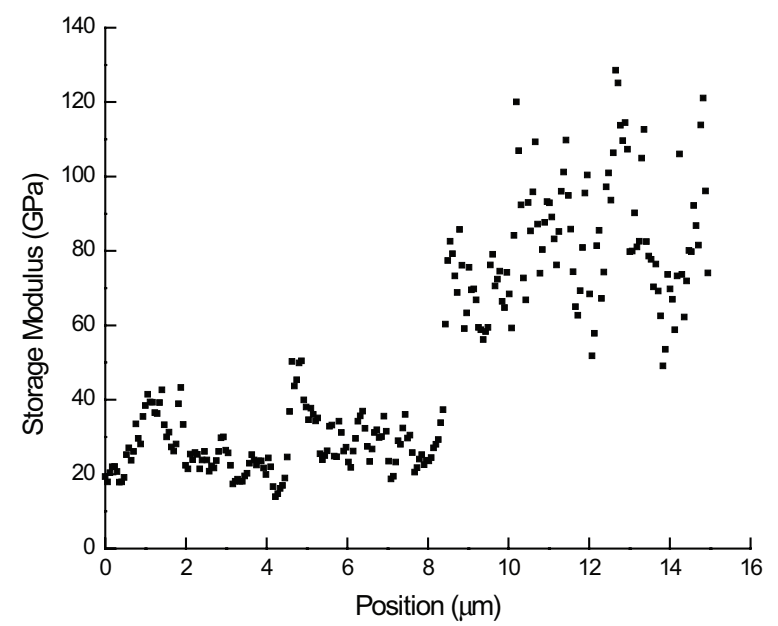

(c)

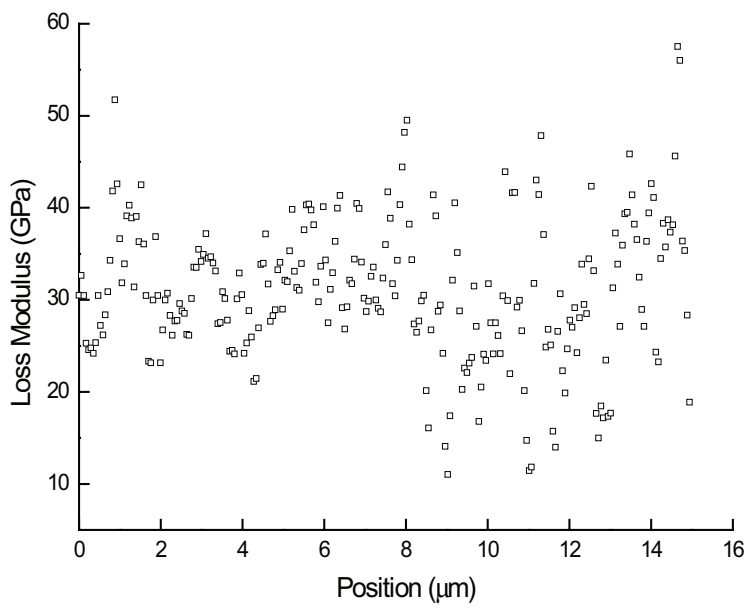

(d)

Figure 9. Storage and loss modulus on interface of control paste. (a) Storage modulus in GPa. (b) Loss modulus in GPa. (c) Storage modulus variation cross-sections. (d) Loss modulus variation cross-sections.

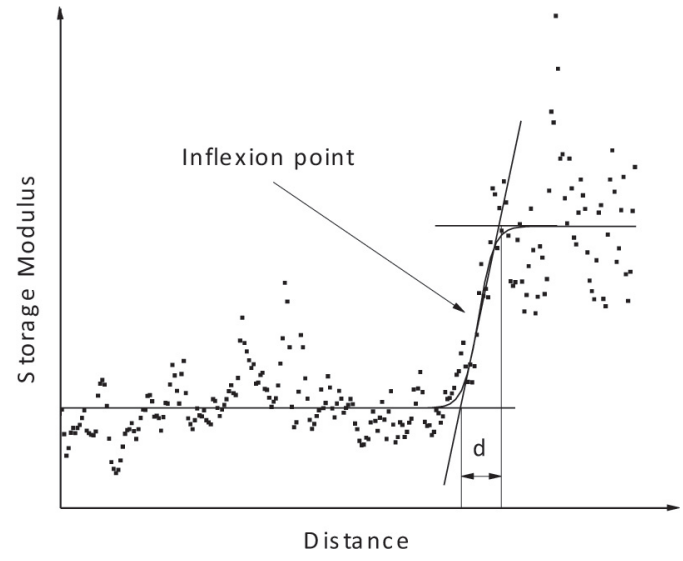

Figure 10. Determination of interface width by storage modulus curve.

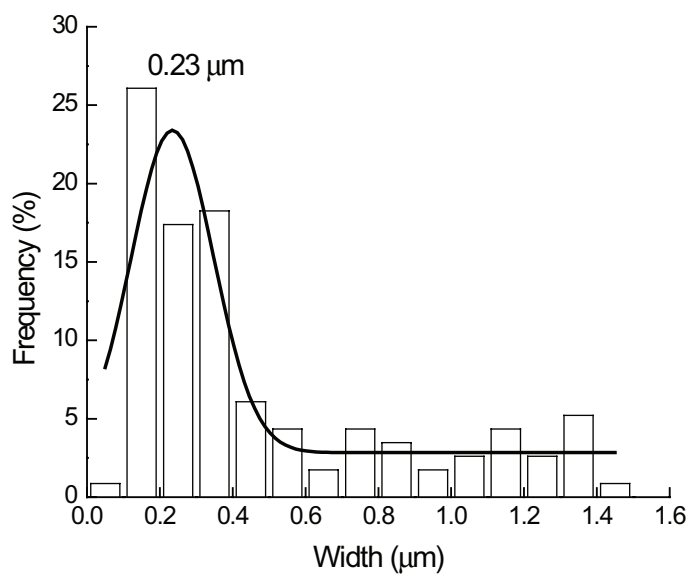

Figure 11. Interface width distribution functions.

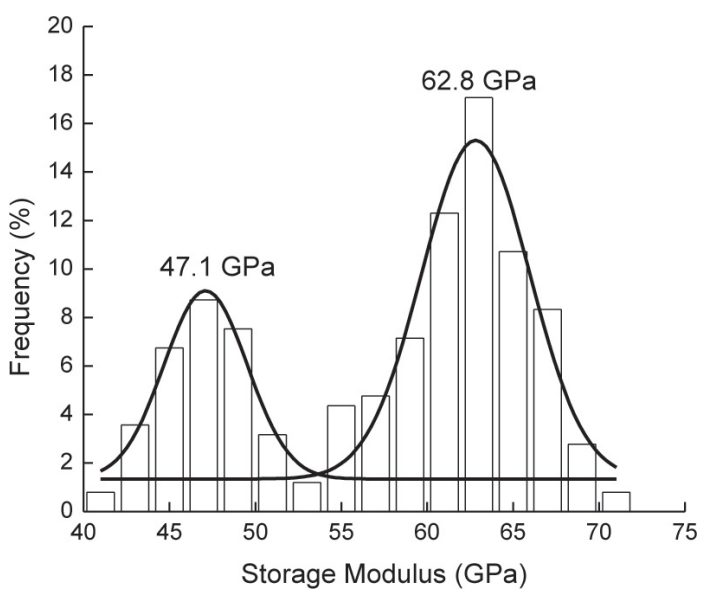

Figure 12. Interface storage modulus distribution functions.

Since the probing remained in the elastic region, the spatial resolution depended only on the radius of the tip and the contact area. The tip radius is determined to be $600 \mathrm{~nm}$ by standard nanoindentation protocol. Thus the contact area, using Equation (10), was calculated as $40 \mathrm{~nm}$ for gel and $28 \mathrm{~nm}$ for cement grain. 


\section{DISCUSSION}

Nanoindentation has been widely used for studying the mechanical properties of materials at micron and submicron levels. In this study, indentations were performed on grid across cement grain/C-S-H gel interface to generate enough data without any bias for a statistical analysis. It was found that the indentation modulus of the region on $\mathrm{C}-\mathrm{S}-\mathrm{H}$ close to the cement grain was apparently higher than the part far away from the interface. This could be due to the limitations of discrete nanoindentation. For Berkovitch diamond tips, the lateral dimension of the indentation is greater than the depth of indentation. Therefore, to avoid error in results due to possible overlapping or interaction between adjacent indentations, a separation is needed. For multiphase materials with large differences in mechanical properties, such as the cement paste, the softer material dictates the minimum separation required, as the indentations in hard phase are far apart, while in soft part they almost touch one another. As shown in Figure 2, the lateral dimension of an indent mark on soft $\mathrm{C}-\mathrm{S}-\mathrm{H}$ gel was about $1 \mu \mathrm{m}$, thus a minimum separation of $3 \mu \mathrm{m}$ was selected to avoid the interaction. As shown by followed modulus mapping results, the interface size was far less than $1 \mu \mathrm{m}$. Thus, this interface cannot be accurately probed by nanoindentation method. The apparent higher value of indentation modulus close to the interface could be the interaction effects of adjacent phase, that is, cement grain. The interface width was determined as less than $5 \mu \mathrm{m}$ for a best estimation using this technique.

Comparing with nanoindentation, the modulus mapping method allowed evaluation of both storage and loss moduli for small areas with high spatial resolution, as shown in Table 2. This permitted the quantitative determinations of these modulus variations at the interface. In modulus mapping mode, the material under the tip is probed within the elastic region. Once the tip force is removed, the material returns to its original shape with no local residual stress or permanent deformation. The current technique can only be used to determine mechanical property variation in a small area (maximum of $50 \mu \mathrm{m} \times 50 \mu \mathrm{m}$ ). This can be extremely useful when investigating narrow transition zone widths and local variations of a local mechanical property; however, for larger areas, this technique would be inconvenient and time consuming since a typical scan of $15 \mu \mathrm{m} \times 15 \mu \mathrm{m}$ takes $45 \mathrm{~min}$.

Table 2. Comparison of nanoindentation and modulus mapping.

\begin{tabular}{lcc}
\hline & $\begin{array}{c}\text { Contact force } \\
(\boldsymbol{\mu N})\end{array}$ & $\begin{array}{c}\text { Spacing } \\
(\mathbf{n m})\end{array}$ \\
\hline Nanoindentation & 1200 & 3000 \\
Modulus mapping & 3.5 & 56 \\
\hline
\end{tabular}

The storage modulus ranges of $\mathrm{C}-\mathrm{S}-\mathrm{H}$ gel and cement grain corresponded well with the ranges of elastic modulus by nanoindentation, which could be due to the fact that the storage modulus represents the part of elastic response of the material. The width of interface between $\mathrm{C}-\mathrm{S}-\mathrm{H}$ gel and cement grain was measured as around $200 \mathrm{~nm}$. This is one order of magnitude lower than the results from nanoindentation, which further validates the higher accuracy of probing by modulus mapping. Multipeak pattern was found for the storage modulus distribution of the interface, suggesting the nonuniform packing density of interface. The interface studied by nanomechanical measurements in our work could be considered as a coating layer on cement grains. This was further verified by scanning electron microscopy (SEM) images, as shown in Figure 13.

This work evaluated the loss modulus of $\mathrm{C}-\mathrm{S}-\mathrm{H}$ gel and unhydrated clinker. The higher loss modulus of $\mathrm{C}-\mathrm{S}-\mathrm{H}$ compared with cement grains is due to the gel features of $\mathrm{C}-\mathrm{S}-\mathrm{H}$. As a result, $\mathrm{C}-\mathrm{S}-\mathrm{H}$ gel is more viscoelastic than cement grains. This is a result of higher energy dissipation as heat while $\mathrm{C}-\mathrm{S}-\mathrm{H}$ gel is deformed in comparison with cement grains. The higher loss modulus makes $\mathrm{C}-\mathrm{S}-\mathrm{H}$ less prone to fracture.

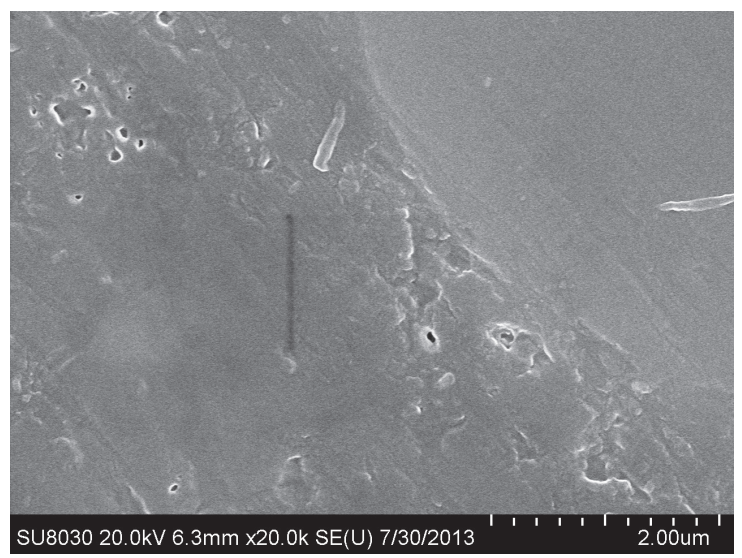

Figure 13. SEM images of interface between $\mathrm{C}-\mathrm{S}-\mathrm{H}$ gel and cement grain.

\section{CONCLUSIONS}

The local nanomechanical properties of interface between $\mathrm{C}-\mathrm{S}-\mathrm{H}$ gel and cement grains were obtained with nanoindentation and modulus mapping. Nanoindentation results provided a rough estimation of interface width of less than $5 \mu \mathrm{m}$. One could attributed this large range to the large step size $(3 \mu \mathrm{m})$ used in indentation. Modulus mapping yielded the interface width of around $200 \mathrm{~nm}$, owing to much higher spatial resolution ( $40 \mathrm{~nm}$ or less) of the viscoelastic modulus imaging.

\section{ACKNOWLEDGMENTS}

The authors would like to acknowledge the financial support for this study from the National Natural 
Science Foundation of China (51378011) and the National Basic Research Program of China (973 Program: 2011CB013800). This work made use of the EPIC and NIFTI facility (NUANCE CenterNorthwestern University), which has received support from the MRSEC program (NSF DMR-1121262) at the Materials Research Center, and the Nanoscale Science and Engineering Center (EEC-0118025/003), both programs of the National Science Foundation, the State of Illinois, and Northwestern University.

\section{REFERENCES}

Acker, P. (2001). Micromechanical analysis of creep and shrinkage mechanisms. In F.-J. Ulm, Z. P. Bazant, \& F. H. Wittmann (Eds.) Creep, shrinkage and durability mechanics of concrete and other quasi-brittle materials. Oxford, UK, Cambridge, MA: Elsevier.

Balooch, G., Marshall, G. W., Marshall, S. J., Warren, O. L., Asif, S. A. S., \& Balooch, M. (2004). Evaluation of a new modulus mapping technique to investigate microstructural features of human teeth. Journal of Biomechanics, 37, 1223-1232.

Constantinides, G., \& UIm, F. J. (2004). The effect of two types of C-S-H on the elasticity of cementbased materials: Results from nanoindentation and micromechanical modeling. Cement and Concrete Research, 34, 67-80.

Constantinides, G., \& Ulm, F.-J. (2007). The nanogranular nature of $\mathrm{C}-\mathrm{S}-\mathrm{H}$. Journal of the Mechanics and Physics of Solids, 55, 64-90.

Constantinides, G., Ulm, F., \& Van Vliet, K. (2003). On the use of nanoindentation for cementitious materials. Materials and Structures, 36, 191-196.

Davydov, D., Jirásek, M., \& Kopecký, L. (2011). Critical aspects of nano-indentation technique in application to hardened cement paste. Cement and Concrete Research, 41, 20-29.

DeJong, M. J., \& UIm, F. J. (2007). The nanogranular behavior of C-S-H at elevated temperatures (up to 700 degrees C). Cement and Concrete Research, $37,1-12$.

Jennings, H. M., Thomas, J. J., Gevrenov, J. S., Constantinides, G., \& Ulm, F. J. (2007). A multitechnique investigation of the nanoporosity of cement paste. Cement and Concrete Research, 37, 329-336.

Jones, C. A., Grasley, Z. C., \& Ohlhausen, J. A. (2012). Measurement of elastic properties of calcium silicate hydrate with atomic force microscopy. Cement and Concrete Composites, 34, 468-477.

Miller, M., Bobko, C., Vandamme, M., \& Ulm, F. J. (2008). Surface roughness criteria for cement paste nanoindentation. Cement and Concrete Research, 38, 467-476.

Mondal, P., Shah, S. P., \& Marks, L. (2007). A reliable technique to determine the local mechanical properties at the nanoscale for cementitious materials. Cement and Concrete Research, 37, 1440-1444.

Mondal, P., Shah, S. P., \& Marks, L. D. (2008). Nanoscale characterization of cementitious materials. ACI Materials Journal, 105, 174-179.

Oliver, W. C., \& Pharr, G. M. (1992). An improved technique for determining hardness and elastic modulus using load and displacement sensing indentation experiments. Journal of Materials Research, 7, 1564-1583.

Reda, M., Shrive, N., \& Gilliott, J. (1999). Microstructural investigation of innovative UHPC. Cement and Concrete Research, 29, 323-329.

Richard, P., \& Cheyrezy, M. (1995). Composition of reactive powder concretes. Cement and Concrete Research, 25, 1501-1511.

Sakulich, A. R., \& Li, V. C. (2011). Nanoscale characterization of engineered cementitious composites (ECC). Cement and Concrete Research, 41, 169-175.

Shah, S. P., \& Ahmad, S. H. (1994). High performance concrete and applications. London, England: Edward Arnold.

Sorelli, L., Constantinides, G., UIm, F. J., \& Toutlemonde, F. (2008). The nano-mechanical signature of ultra high performance concrete by statistical nanoindentation techniques. Cement and Concrete Research, 38, 1447-1456.

Tribollndenter User Manual. (2006). Minneapolis, MN: Hysitron Inc.

Vandamme, M., Ulm, F. J., \& Fonollosa, P. (2010). Nanogranular packing of C-S-H at substochiometric conditions. Cement and Concrete Research, 40, 14-26.

Velez, K., Maximilien, S., Damidot, D., Fantozzi, G., \& Sorrentino, F. (2001). Determination by nanoindentation of elastic modulus and hardness of pure constituents of Portland cement clinker. Cement and Concrete Research, 31, 555-561.

Xiao, J., Li, W., Sun, Z., Lange, D. A., \& Shah, S. P. (2013). Properties of interfacial transition zones in recycled aggregate concrete tested by nanoindentation. Cement and Concrete Composites, 37, 276-292.

Xu, J., \& Yao, W. (2011). Nano-scratch as a new tool for assessing the nano-tribological behavior of cement composite. Materials and Structures, 44, 1703-1711. 